\title{
Update on Pituitary Folliculo-Stellate Cells
}

\author{
Maria Pires ${ }^{1}$ and Francisco Tortosa ${ }^{1,2 *}$ \\ ${ }^{1}$ Experimental Pathology Laboratory/Institute of Pathology, University of Lisbon, Portugal \\ ${ }^{2}$ Department of Medicine/Endocrinology, Autonomous University of Barcelona (UAB), Spain
}

*Corresponding author: Francisco Tortosa, Experimental Pathology Laboratory/Institute of Pathology, Faculty of Medicine, University of Lisbon, Av. Prof. Egas Moniz, 1649-028 Lisbon, Portugal, Tel: +351-968-383-939, Fax: +351217-805-602, E-mail: franciscotortosa.pathology@gmail.com

\begin{abstract}
Folliculo-stellate cells (FSCs) are a non-endocrine population of sustentacular-like, star-shaped and follicle-forming cells, which contribute about $5-10 \%$ of elements from the anterior pituitary lobe. First identified with electron microscopy as non-hormone secreting accessory cells, light microscopy has revealed many of their cytophysiological features, and is known as positive for S-100 protein, a marker for FSCs. They are currently considered as functionally and phenotypically heterogeneous. Secretory cells are in close interconnection with this agranular functional units in an interactive endocrine networking. Due to FSCs communication with their endocrine neighbours, this opens the door to considering the pituitary as a cellular puzzle more ordered than the first thought. After a long period of pituitary research, many issues remain unsolved. In spite of many morphological and cytophysiological studies recently reported, a precise understanding of the major functions of FSCs in the pituitary gland remains unknown. New studies about the origin and differentiation of FSCs are expected to provide many relevant answers with respect to the debate about physiopathology of the pituitary gland. Here we review the characteristics of FSCs and their uncertain functions in the adenohypophysis, with focus on the present research points that we consider fundamental, such as their importance as stem cells, in the process of maturation and aging, and in the pathogenesis of pituitary tumors.
\end{abstract}

\section{Keywords}

Folliculo-stellate cells, S-100 protein, Pituitary tumor

\section{Introduction}

The pituitary gland (pituitary) is a complex endocrine regulator, small but still fundamental to the human body. It is an intermediary body from the signal exchanges between the hypothalamus and peripheral organs, with important functions in physiological processes such as growth, reproduction, metabolism and immune response. Located in the sella turcica, has anteriorly the tubercle of the saddle and the optic chiasm, posteriorly the dorsum sellae and the brainstem and superiorly the hypothalamus [1]. Anatomically and functionally, this gland owns two lobes: the adenohypophysis (anterior pituitary-divided into two regions: pars tuberalis and pars distalis), which derives from the ectoderm and secretes hormones, and neurohypophysis (posterior pituitary-pars nervosa) derived from hypothalamic neuronal axons. A third lobe (pars intermedia) is a smaller avascular zone rough and poorly defined in humans (it regresses at about the $15^{\text {th }}$ week of gestation and become absent from the adult human pituitary gland). The pituitary gland is constituted by granule cells producing specific hormones that act by controlling the growth (growth hormone-GH-), lactation (prolactin-PRL-), thyroid function (triiodothyronine-T3- and thyroxine-T4-), adrenal function (adrenocorticotropic hormone-ACTH-) and gonadal function (follicle-stimulating hormone-FSH- and luteinizing hormone-LH-) [2]. Additionally, the neurons that are part of the posterior pituitary secrete vasopressin (antidiuretic hormone-ADH-), which is the hormone involved in maintaining water balance, and oxytocin, that play a role in uterine contraction and lactation. The negative feedback loop is the basic mechanism for controlling all endocrine glands [3]. These hormonal cells (granular) are associated with non-hormonal cells (agranular), of which the folliculo-stellate cells (FSCs) are the highest number [4].

FSCs are primarily non-hormone secreting accessory elements which contribute about $5-10 \%$ of cells from the anterior pituitary [5]. These non-secreting cells clearly contribute to the regulation and maintenance of the population of hormonal cells, by delivering stimulating factors and inhibitors of the hypothalamus and to transport secretory products from the gland [6].

Since the identification of the FSCs to nowadays, many features and functions have been identified. Here we review the characteristics of FSCs and their uncertain functions in the adenohypophysis, with focus on the present research points that we consider fundamental, such as their importance as stem cells, in the process of maturation and aging, and in the pathogenesis of pituitary tumors.

\section{Non-Hormonal Adenohypophyseal Cells - FSCs}

As historical context, the study of FSCs in the anterior pituitary dates returns more than half a century. In the early days of electron microscopy, the anterior pituitary was considered an interesting body for studies at this unit, and the peculiar nature of the FSCs was soon discovered [5]. They were first described in 1953 by Rinehart, et al. but were originally designated as chromophobe cells because of the absence of their cytoplasmic affinity to dyes [7]. Since the beginning of their discovery, many aspects of the FSCs were investigated, and the cells that were initially considered simple structures have escaped to a real unveiling of what their importance may be.

\section{ClinMed International Library}

Citation: Pires M, Tortosa F (2016) Update on Pituitary Folliculo-Stellate Cells. Int Arch Endocrinol Clin Res 2:006

Received: September 30, 2016: Accepted: October 24, 2016: Published: October 27, 2016 Copyright: $@ 2016$ Pires M, et al. This is an open-access article distributed under the terms of the Creative Commons Attribution License, which permits unrestricted use, distribution, and reproduction in any medium, provided the original author and source are credited. 


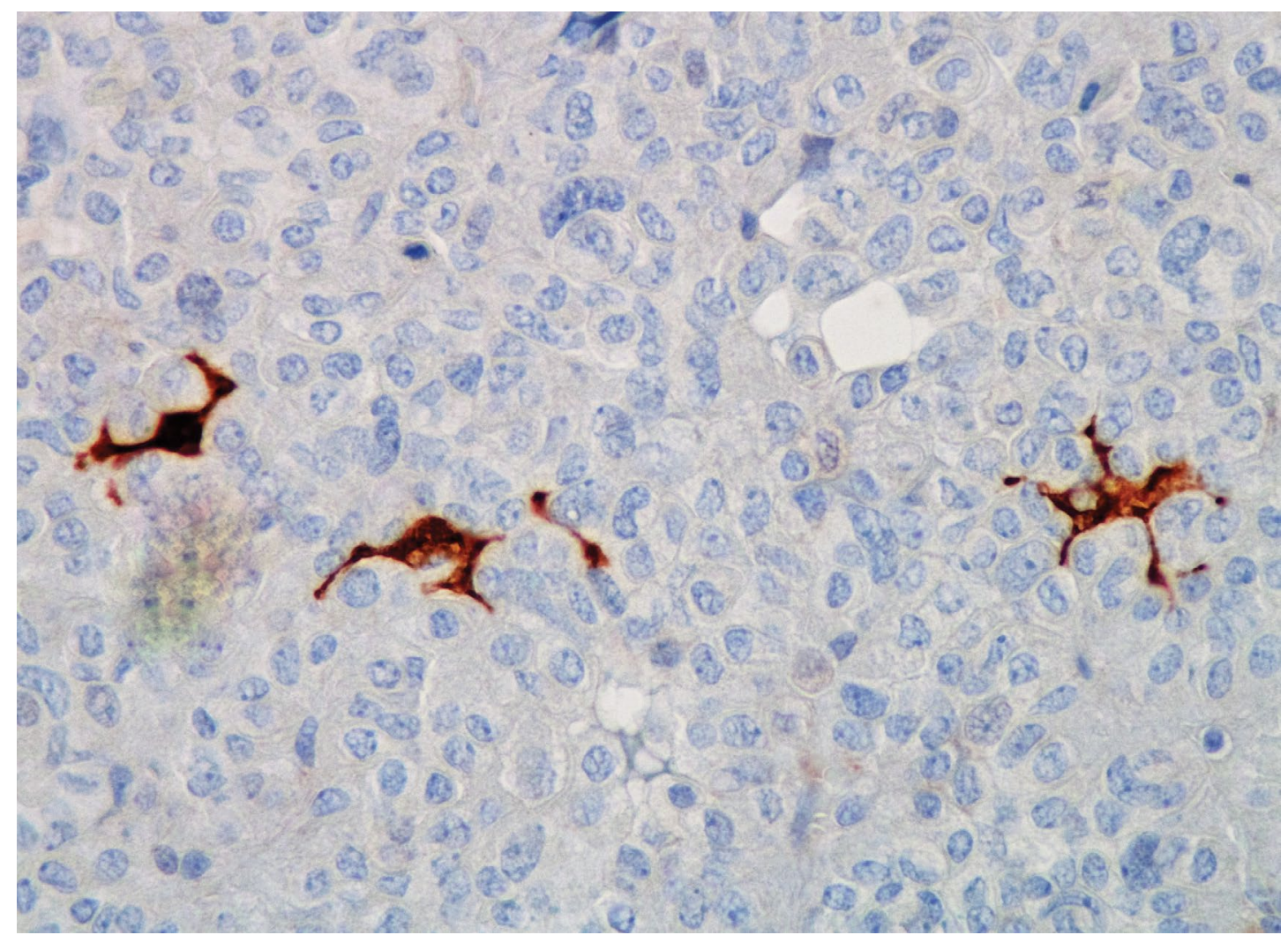

Figure 1: Folliculo-stellate cells immunoreactive for S-100 protein (S-100, 400x).

\section{Morphology}

The first cells of the anterior pituitary where it a large-scale network organization was shown to exist were the FSCs [6]. In 1957, interdigitated configuration of many cells was observed in the anterior pituitary gland. The FSCs has been reported and described as adrenocorticotroph-like cells without secretory granules and arranged around the follicles [8]. In 1972, Vila-Porcile, based on their star-like morphology and their ability to form structures around the acini, named these cells as folliculo-stellate cells [9].

Follicles are found throughout the adenohypophysis as lumens that are lined mainly by agranular or poorly granulated cells joined at their apex by junctional complexes. Traditionally, the polygonal cells surrounding these follicles, with long cytoplasmic processes were named follicular cells (FC) [10]. They stain for cytokeratins and are often observed around areas of necrosis [11]. On the other hand, folliculostellate (FS) cells are a specific subtype of cell in the normal human pituitary gland with immunoreactivity for S- 100 protein [1113]. These cells are agranular and do not exhibit immunoreactivity for the classic adenohypophysial hormones. They have a characteristic stellate morphology. Because of confusion with the FC, some authors have suggested that these cells should be called "stellate cells" [13]. Both were mostly considered to be supporting structures for the endocrine cells, but neither their origin nor their functional significance is well understood $[5,11,14,15]$.

Due to the fact that FSCs are not endocrine cells, immunohistochemical detection with an antibody against a specific hormone cannot be used. This made it difficult to study FSCs and its research delayed compared to pituitary cells that are producing hormones. Many characteristics of FSCs remained unknown until the S-100 protein (S-100) was considered a cell marker [16]. S-100 is a calcium flux regulator protein which was first isolated from the central nervous system (CNS) [17]. Indeed, S-100 has been a powerful tool that allows FSCs viewing under an optical microscope [16] (Figure 1).

These cells are also positive for glial fibrillary acidic protein (GFAP) suggesting that this cell type may represent an astrocyte- or microglia-like cell type [1]. Several authors cited by Perez-Castro, et al. [1], consider this hypothesis by their phagocytic capabilities and glia-like supportive functions within the pituitary, which are involved in the regulation of ion homeostasis, water transport and protection from damage caused by irradiation or free radical. Several studies were made using cell counts in order to assess the specificity of these immunohistochemical markers, but many inconsistencies were found across studies, which led to the absence of real progress on the nature and physiological role of FSCs.

Horvath and Kovacs [18] consider that S-100 and GFAP are human FSC markers only in limited contexts. These authors believe that none of the markers is suitable for quantification, and the sequence of the second marker expression cannot be unequivocally determined by cell morphology. Sands, et al. [19] reported that S-100 serves as a neurotrophic and glial maturation factor in the CNS that has also been detected in some types of pituitary cells during fetal growth.

Another way to define the FSCs is by absorbing the fluorescence of the peptide SS-Ala-Lys-Ne-AMCA (AMCA) by means of specific proton pump cell [20]. Taking advantage of selective absorption of AMCA, it was possible to confirm the organization of the FSCs in a $3 \mathrm{D}$ anatomical network [9].

\section{Functions}

The early stage of development and organization of the FSCs has not been thoroughly investigated. However, observations were subsequently made in adult FSCs, and it was demonstrated that they form an excitable network [21]. Immunohistochemical and ultrastructural studies have shown that FSCs form a network within the anterior pituitary in which the cellular extensions of this cells are connected among each other mechanically and functionally through desmosomes and gap junctions (small pores that permit the intercellular exchange of molecules smaller than 1,000 Da), respectively.

According to Le Tissier, et al. [6] the intrinsic excitability of FSCs and expression of connexin 43, a peptide marker of gap junctions, both between themselves and with endocrine cells suggests that FSCs might play a role in the coordination activity in groups of cells from 
the endocrine system in a local or distal level, besides facilitating through the gap junctions the transmission signal the hypothalamic neurons that project to the pars tuberalis. Another function of the FSCs is related to pituitary functional plasticity that can be inferred from the modification of the number of gap junctions, and its morphological relationship with altered hormonal cells in response to physiological changes [6].

In order to perform different functions, FSCs produce a range of growth factors that modulate and alter the function of the endocrine pituitary cells: the interleukin-6 (IL-6) [22-24], the vascular endothelial growth factor (VEGF) [25], the basic fibroblast growth factor (FGF-2) [26] and annexin-1 [27], and express receptors for pituitary hormones [28], suggesting a role of these cells in the mechanism of "short-feedback loop" in addition to hormonal cell modulation [6].

Clues to FSC function should also be able to be gleaned from the morphological similarities they share with brain astrocytes, dendritic cells in the lymph tissue, Langerhans cells of the skin, sustentacular cells in the adrenal gland and Sertoli cells in the testis. Interestingly, all of these cells are positive for the S-100 protein [4]. For example, they are believed to have a supportive role similar to that played by the S-100positive sustentacular cells of the adrenal medulla and paraganglia.

\section{FSCs-Stem cells in the adult?}

Inoue, et al. [4] quotes several authors on the possibility of FSCs being a type of stem cells with the potential to differentiate into endocrine cells. Recent studies were able to describe a population of cells with stem cell characteristics in the adult rat pituitary [2931]. It was found that these cells may have the capacity for selfrenewal, being capable of differentiating into all types of anterior pituitary hormones cells $[29,30]$. However, the process is not uniform and it was found that the adult positive cells are identified by Sox 2 transcription factor (core transcription factor in maintaining the selfrenewal and pluripotency of the stem cells), which may represent a distinct population compared to the embryo and newborn [32], and are mainly found in the crevice that separates the anterior lobe and intermediate but also scattered in the anterior lobe of the pituitary gland [33]. It is necessary to highlight the fact that the transcription factor Sox2 expressed in all cells of Rathke's pouch, the structure of which eventually gives rise to the anterior pituitary [34]

The importance of these findings relates to the fact that the stem cells, after the renewal of the pituitary gland and cell response to physiological changes, are also involved in repairing damage to pituitary cells $[35,36]$. The nature of the signals that drive their proliferation and differentiation into different cell types is not clear. An in vitro system to study the differentiation of stem cells in pituitary cells [37] has provided important information about the factors required for the process. Notably, embryonic stem cell can also be induced to differentiate into structures that resemble either of Rathke's pouch, as they have the ability to produce pituitary hormones [37]. The organization of Sox 2 positive cells was described [38], showing that the cells that line the cleft have the ability to contact with the cells dispersed within the lobe. This organization suggests that the long-range communication between these putative stem cells may be important in determining whether differentiation pathways, proliferation, or maintenance of stem cell characteristics.

Nolan and Levy [39] through studies in rats suggest that the differentiated cells may be sensitive to the size of their population and choose to differentiate into stem cells, however the whole mechanism is still unclear. An interesting hypothesis is that the organization of the "network" is responsible with the control of the cell population and the presence of multiple populations can provide a mechanism to trigger the differentiation of stem cells [6].

Until the present, several studies support the existence of multipotent stem cells in the adult pituitary, but still not much is known about its function and significance because not all of them are in complete agreement. Bilezikjian, et al. [14] and Vankelecom [40] supposed that FSCs represent anterior pituitary stem cells.
According to Vankelecom, et al. [41], a number of adult tissues are able to regenerate cells after destruction by physical or chemical impact, as in muscle tissue after injury or toxin injection. In other organs, involving stem cells is less clear in the repair or present only under certain conditions, as in liver due to illness or chemical attacks. It should be noted that there are many disease states where tissues are committed and if any response of stem cells, they may not be able to fully repair the tissue: the neural-stem cells are not able to restore the damages of degenerative disease (e.g. Parkinson's disease) and cardiac stem cells do not address the damage caused by myocardial infarction. The adult pituitary shows regenerative capabilities, but the mechanisms and the contribution of stem cells may differ by the degree and nature of the condition and the type of cell affected. According to this author there are issues that need to be explored: clarify whether these processes also occur in the pituitary disease conditions (e.g. Sheehan syndrome, hypophysitis), or after tissue damage by tumor resection or irradiation [41]. Although the functional significance of cells in stem-cell homeostasis of adult pituitary, the potential recovery of an injury, and deficits endocrine tumor pathogenesis have not been formally established. FSCs are found in large numbers in the compressed adenohypophysis at the periphery of adenomas and other pituitary lesions, such as abscesses and amyloid deposits, and in the residual hypophysis after surgery, but not adjacent to metastatic tumor deposits, infarcts, or Rathke cleft cysts [42], which could explain the fact that the adenohypophysis does not undergo regeneration after partial infarction or resection.

\section{FSCs and aging process}

Some investigators supposed that FSCs may be involved in catabolic and trophic processes and with the transport of macromolecules. Previous studies indicated that the FSCs can be used to modulate hormone production and secretion in anterior pituitary through local paracrine actions $[15,43]$. For this purpose, the interdigitations and the hormone producing cells can endure the presence of intercellular communication. Herkenham [44] suggests a role for the FSCs in a two-way communication between the immune and endocrine systems. This author reported that the origin of these non-hormone secreting anterior pituitary interstitial cells, according to their markers expression might be neuroectodermal and also possibly be glial in nature [44]. On the other hand, their phagocytic capacities, IL-6 secretion, and the fact that they share some immunohistochemical, ultrastructural and functional characteristics with lymphoid dendritic cells, suggests that probably their subpopulation could be derived from the monocyte- dendritic cells-macrophage lineage [45]. FSCs act as phagocytes of both cellular debris and apoptotic bodies, sharing properties with dendritic cells and also with macrophages, which support kinship between them and cells of the mononuclear phagocytic system [44,46].

Although the anterior pituitary is very important to maintain homeostasis of the human body, studies on their structural changes during the aging process are scarce. Sano, et al. [47] described some of these changes by assessing the changes related to age through the connective tissue analysis of the anterior pituitary and endocrine cells using histologic analysis and semi-quantitative methods.

However, there is a lack of data in the literature on aging changes in the FSCs and those that have been conducted using animal resources and obtained conflicting results [48]. Cónsole, et al. [49] evaluated the number of anterior pituitary cells S-100 positive during the aging process. This study showed a progressive decrease in FSCs connected to age in old and senescent rats (20 months and 29 months, respectively) compared to young (3 months). The analysis of morphometric parameters showed a significant decrease on its volume and cell density in the old and senescent rats compared to young in both genders.

Several studies have found approaches, as well as the presence of distinct levels of FSCs, increased during the postnatal life, and while some other studies have shown increased FSCs associated with age [45]. 
Pavlovic, et al. [48] before the results lifted a question: If there is an increase with age, which could be the possible causes and consequences for the function of the anterior pituitary? Based on literature data, they conducted a study to quantify the FSCs in the anterior pituitary samples at different ages and in a roundabout way tried to establish its possible impact on the functioning of the anterior pituitary gland, during human aging. They concluded that FSCs increases its presence in the human anterior pituitary during the aging process. However, this increase is only significant in earlier cases, and perhaps taken together with changes related to age of the immune system, and characterized by chronic inflammatory condition of low quality and high levels of blood cytokines present in these cases. The above conditions can stimulate FSCs to proliferate and exhibit their paracrine actions in endocrine cells of the anterior pituitary and, ultimately, participate in aging changes of the hypothalamic-pituitary axis. Therefore, future studies should include, in addition to quantitation of FSCs, an appropriate biochemical and/ or immunohistochemical simultaneous analysis of levels of their products originated from paracrine function, in cases with different ages.

\section{FSCs and pituitary tumors}

Pituitary tumors are common in humans, and might cause various pathological complications such as growth disorders, sexual dysfunction, infertility, obesity, metabolic and mood disorders [50]. The tumors may arise from any cell of the anterior pituitary [2] Pituitary adenomas (PA) are quite common and have been reported to occur in about $15-20 \%$ of the general population, a third of which is clinically significant $[51,52]$. Most PA correspond to primary tumors that have a slow growth, and various hormonal and proliferative behaviour [50].

We can find an extensive type of endocrine symptoms resulting from hormonal hypersecretion, but sometimes the space occupied by the tumor itself, particularly the rapidly growing causing an intracranial mass, may cause other problems such as decreased secretion of some hormones, visual disturbances, headache and sleep problems [2]. In addition to the clinical (functional) and radiological classification may also be classified histologically, which allows to redefine the hormonal nature of the adenomas [53].

The progression mechanism of PA in more aggressive and invasive tumors is still unclear, and it has not been possible yet to find a marker that allows assisting the clinician on its prognosis. It is in this very specific point of the pathology of PA that Fauquier, et al. [54] refers to FSCs as supporting cells, with a dense network and decisive roles in the coordination of cellular activity, as a determining factor not only at physiological but also pathological level. Some authors indicate that there are certain endocrine tumors (pheochromocytomas or paragangliomas) where the reduction or absence of these sustentacular cells indicates a worse prognosis than when they are present, which is suggestive of their metastatic potential $[55,56]$. But here, once again, the results are not consistent. Recently, a study conducted by Tortosa, et al. [57] found that the predictive factor of tumor aggressiveness for PA, is not represented by a low value of S-100 in FSCs, not allowing the selection of patients for intensive post-operative treatment. This study shows that the labelling index for S-100 protein cannot be used as a prognostic factor of aggressive behaviour for pituitary tumors. Reminding that a nonnegligible part of PA are not ultimately amenable to cure by either conventional pharmacotherapy or surgery, perhaps FSCs may offer some solutions in the pathogenesis of PA.

Special mention for the spindle cell oncocytoma (SCO), an unusual and controversial tumor. This is a spindled to epithelioid, oncocytic, non-neuroendocrine neoplasm of the pituitary gland [58]. It was first reported in 2002 by Roncaroli [59], who proposed that the origin of this tumor was in the FSCs of the anterior pituitary. Till the date, the histogenesis of SCO remains unresolved. Initially, a derivation from FSCs of the adenohypophysis was postulated on the basis of the immunoprofile (in particular galectin- 3 and annexin
A1 expression) and ultrastructural features. However, finding that not only pituicytomas, but also granular cell tumors of the sellar region and SCO express the nuclear transcription factor TTF1, like pituicytes of the developing and mature neurohypophysis, suggests a pituicyte derivation [60]. So, the difference between this tumor and the tumor called "pituicytoma", which is attributed to stromal cells of the posterior lobe, is not clear.

\section{Conclusion}

FSCs are non-hormone secreting accessory cells that have an important role in the integration of information on the anterior pituitary auto/paracrine loops. Thus, this cell networking within the pituitary could have a privileged role in coordinating the activities of distant cells in both physiological and pathological conditions. However, the physiopathological role of the intrapituitary FSC network for the regulation of the anterior pituitary is still poorly understood. After a long period of pituitary research, recent evidence has been involving FSCs with facets of adenohypophyseal machinery as manifold as paracrine regulation, cellular turnover, and neuroimmune crosstalk, but many issues remain unsolved. New studies about the origin and differentiation of FSCs are expected to provide several answers with respect to the debate about physiopathology of the pituitary gland.

\section{Acknowledgments}

We thank Ana Raquel Henriques for help with the translation into English.

\section{References}

1. Perez-Castro C, Renner U, Haedo MR, Stalla GK, Arzt E (2012) Cellular and molecular specificity of pituitary gland physiology. Physiol Rev 92: 1-38.

2. Yeung CM, Chan CB, Leung PS, Cheng $\mathrm{CH}$ (2006) Cells of the anterior pituitary. Int J Biochem Cell Biol 38: 1441-1449.

3. Mihai R (2014) Physiology of the pituitary, thyroid, parathyroid and adrena glands. Surgery 32: 504-512.

4. Inoue K, Couch EF, Takano K, Ogawa S (1999) The structure and function of folliculo-stellate cells in the anterior pituitary gland. Arch Histol Cytol 62: 205-218.

5. Allaerts W, Vankelecom $\mathrm{H}$ (2005) History and perspectives of pituitary folliculo-stellate cell research. Eur J Endocrinol 153: 1-12.

6. Le Tissier PR, Hodson DJ, Lafont C, Fontanaud P, Schaeffer M, et al. (2012) Anterior pituitary cell networks. Frontier Neuroendocrinol 33: 252-266.

7. Rinehart JF, Farquhar MG (1953) Electron microscopic studies of the anterior pituitary gland. J Histochem Cytochem 1: 93-113.

8. Farquhar MG (1957) 'Corticotrophs' of the rat adenohypophysis as revealed by electron microscopy. Anatomical Record 127: 291.

9. Vila-Porcile $E$ (1972) The network of the folliculo-stellate cells and the follicles of the adenohypophysis in the rat (pars distalis). Z Zellforsch Mikrosk Anat 129: 328-369.

10. Horvath E, Kovacs K, Penz G, Ezrin C (1974) Origin, possible function and fate of "follicular cells" in the anterior lobe of the human pituitary. Am J Pathol 77: $199-212$

11. Yamashita M, Qian ZR, Sano T, Horvath E, Kovacs K (2005) Immunohistochemical study on so-called follicular cells and folliculostellate cells in the human adenohypophysis. Pathol Int 55: 244-247.

12. Höfler H, Walter GF, Denk H (1984) Immunohistochemistry of folliculostellate cells in normal human adenohypophyses and in pituitary adenomas. Acta Neuropathol 65: 35-40.

13. Girod C, Trouillas J, Dubois MP (1985) Immunocytochemical localization of S-100 protein in stellate cells (folliculo-stellate cells) of the anterior lobe of the normal human pituitary. Cell Tissue Res 241: 505-511.

14. Bilezikjian LM, Leal AM, Blount AL, Corrigan AZ, Turnbull AV, et al. (2003) Rat anterior pituitary folliculostellate cells are targets of interleukin-1 beta and a major source of intrapituitary follistatin. Endocrinology 144: 732-740.

15. Acosta M, Filippa V, Mohamed F (2010) Folliculostellate cells in pituitary pars distalis of male viscacha: immunohistochemical, morphometric and ultrastructural study. Eur J Histochem 54: e1.

16. Devnath S, Inoue K (2008) An insight to pituitary folliculo-stellate cells. J Neuroendocrinol 20: 687-691.

17. Moore BW (1965) A soluble protein characteristic of the nervous system. Biochem Biophys Res Commun 19: 739-744. 
18. Horvath E, Kovacs K (2002) Folliculo-stellate cells of the human pituitary: a type of adult stem cell? Ultrastruct Pathol 26: 219-228.

19. Sands SA, Gary KA, Chronwall BM (1995) Transient expression of S-100 by melanotropes of the rat pituitary intermediate lobe during development. Int $J$ Dev Neurosci 13: 567-576.

20. Otto C, tom Dieck S, Bauer K (1996) Dipeptide uptake by adenohypophysia folliculostellate cells. Am J Physiol 271: C210-217.

21. Fauquier T, Guérineau NC, McKinney RA, Bauer K, Mollard P (2001) Folliculostellate cell network: a route for long-distance communication in the anterior pituitary. Proc Natl Acad Sci U S A 98: 8891-8896.

22. Correa-de-Santana E, Fröhlich B, Labeur M, Páez-Pereda M, Theodoropoulou M, et al. (2009) NOD2 receptors in adenopituitary folliculostellate cells: expression and function. J Endocrinol 203: 111-122.

23. Gloddek J, Lohrer P, Stalla J, Arzt E, Stalla GK, et al. (2001) The intrapituitary stimulatory effect of lipopolysaccharide on ACTH secretion is mediated by paracrine-acting IL-6. Exp Clin Endocrinol Diabetes 109: 410-415.

24. Lohrer P, Gloddek J, Nagashima AC, Korali Z, Hopfner U, et al. (2000) Lipopolysaccharide directly stimulates the intrapituitary interleukin-6 production by folliculostellate cells via specific receptors and the p38alpha mitogen-activated protein kinase/nuclear factor kappaB pathway. Endocrinology 141: 4457-4465.

25. Leung DW, Cachianes G, Kuang WJ, Goeddel DV, Ferrara N (1989) Vascula endothelial growth factor is a secreted angiogenic mitogen. Science 246 1306-1309.

26. Amano O, Yoshitake Y, Nishikawa K, Iseki S (1993) Immunocytochemica localization of basic fibroblast growth factor in the rat pituitary gland. Arch Histol Cytol 56: 269-276.

27. Theogaraj E, John CD, Christian HC, Morris JF, Smith SF, et al. (2005) Perinatal glucocorticoid treatment produces molecular, functional, and morphological changes in the anterior pituitary gland of the adult male rat. Endocrinology 146: 4804-4813

28. Brokken LJ, Leendertse M, Bakker O, Wiersinga WM, Prummel MF (2004) Expression of adenohypophyseal-hormone receptors in a murine folliculostellate cell line. Horm Metab Res 36: 538-541.

29. Chen J, Hersmus N, Van Duppen V, Caesens P, Denef C, et al. (2005) The adult pituitary contains a cell population displaying stem/progenitor cell and early embryonic characteristics. Endocrinology 146: 3985-3998.

30. Fauquier T, Rizzoti K, Dattani M, Lovell-Badge R, Robinson IC (2008) SOX2 expressing progenitor cells generate all of the major cell types in the adult mouse pituitary gland. Proc Natl Acad Sci U S A 105: 2907-2912.

31. Garcia-Lavandeira M, Quereda V, Flores I, Saez C, Diaz-Rodriguez E, et al (2009) A GRFa2/Prop1/stem (GPS) cell niche in the pituitary. PLoS One 4 e4815.

32. Gleiberman AS, Michurina T, Encinas JM, Roig JL, Krasnov P, et al. (2008) Genetic approaches identify adult pituitary stem cells. Proc Natl Acad Sci U S A 105: 6332-6337.

33. Rizzoti K (2010) Adult pituitary progenitors/stem cells: from in vitro characterization to in vivo function. Eur J Neurosci 32: 2053-2062.

34. Kelberman D, Rizzoti K, Avilion A, Bitner-Glindzicz M, Cianfarani S, et al. (2006) Mutations within Sox2/SOX2 are associated with abnormalities in the hypothalamo-pituitary-gonadal axis in mice and humans. J Clin Invest 116 2442-2455.

35. Nolan LA, Kavanagh E, Lightman SL, Levy A (1998) Anterior pituitary cell population control: basal cell turnover and the effects of adrenalectomy and dexamethasone treatment. J Neuroendocrinol 10: 207-215.

36. Ghasemi N, Razavi S (2014) Transdifferentiation potential of adipose- derived stem cells into neural lineage and their application. J Histol Histopathol 1: 12

37. Suga H, Kadoshima T, Minaguchi M, Ohgushi M, Soen M, et al. (2011) Selfformation of functional adenohypophysis in three-dimensional culture. Nature 480: $57-62$.

38. Mollard P, Hodson DJ, Lafont C, Rizzoti K, Drouin J (2012) A tridimensional view of pituitary development and function. Trends Endocrinol Metab 23: 261 269.
39. Nolan LA, Levy A (2006) A population of non-luteinising hormone/ nonadrenocorticotrophic hormone-positive cells in the male rat anterior pituitary responds mitotically to both gonadectomy and adrenalectomy. $J$ Neuroendocrinol 18: 655-661.

40. Vankelecom $\mathrm{H}$ (2007) Non-hormonal cell types in the pituitary candidating for stem cell. Semin Cell Dev Biol 18: 559-570.

41. Vankelecom H, Chen J (2014) Pituitary stem cells: where do we stand? Mol Cell Endocrinol 385: 2-17

42. Nishioka H, Llena JF, Hirano A (1991) Immunohistochemical study of folliculostellate cells in pituitary lesions. Endocr Pathol 2: 155-160.

43. Vankelecom H, Denef C (1997) Paracrine communication in the anterior pituitary as studied in reaggregate cell cultures. Microsc Res Tech 39: 150 156.

44. Herkenham M (2005) Folliculo-stellate (FS) cells of the anterior pituitary mediate interactions between the endocrine and immune systems. Endocrinology 146: 33-34.

45. Allaerts W, Salomon B, Leenen $\mathrm{PJ}$, van Wijngaardt $\mathrm{S}$, Jeucken $\mathrm{PH}$, et al. (1997) A population of interstitial cells in the anterior pituitary with a hematopoietic origin and a rapid turnover: a relationship with folliculo-stellate cells? J Neuroimmunol 78: 184-197.

46. Vankelecom $H$, Matthys $P$, Van Damme J, Heremans $H$, Billiau A, et al. (1993) Immunocytochemical evidence that S-100-positive cells of the mousse anterior pituitary contain interleukin-6 immunoreactivity. J Histochem Cytochem 41: 151-156.

47. Sano T, Kovacs KT, Scheithauer BW, Young WF Jr (1993) Aging and the human pituitary gland. Mayo Clin Proc 68: 971-977.

48. Pavlovic M, Jovanovic I, Ugrenovic S, Vasovic L, Krstic M, et al. (2013) Morphometric analysis of the human anterior pituitary's folliculostellate cells during the aging process. Ann Anat 195: 231-237.

49. Cónsole GM, Jurado SB, Riccillo FL, Gómez Dumm CL (2000) Immunohistochemical and ultrastructural study of pituitary folliculostellate cells during aging in rats. Cells Tissues Organs 167: 25-32.

50. Asa SL, Ezzat S (2002) The pathogenesis of pituitary tumours. Nat Rev Cancer 2: 836-849.

51. Asa SL, Ezzat S (1998) The cytogenesis and pathogenesis of pituitary adenomas. Endocr Rev 19: 798-827.

52. Ezzat S, Asa SL, Couldwell WT, Barr CE, Dodge WE, et al. (2004) The prevalence of pituitary adenomas: a systematic review. Cancer 101: 613-619.

53. Tortosa F, Webb SM (2016) Novel aspects in histopathology of the pituitary gland. Endocrinología y Nutrición (Article in press).

54. Fauquier T, Lacampagne A, Travo P, Bauer K, Mollard P (2002) Hidden face of the anterior pituitary. Trends Endocrinol Metab 13: 304-309.

55. Unger P, Hoffman K, Pertsemlidis D, Thung S, Wolfe D, et al. (1991) S100 protein-positive sustentacular cells in malignant and locally aggressive adrenal pheochromocytomas. Arch Pathol Lab Med 115: 484-487.

56. van der Harst $E$, Bruining $H A$, Jaap Bonjer $H$, van der Ham $F$, Dinjens WN et al. (2000) Proliferative index in phaeochromocytomas: does it predict the occurrence of metastases? J Pathol 191: 175-180.

57. Tortosa F, Pires M, Ortiz S (2016) Prognostic implications of folliculo-stellate cells in pituitary adenomas: relationship with tumoral behavior. Rev Neurol 63: 297-302.

58. Lopes MBS, Fuller GN, Roncaroli F, Wesseling P (2016) Spindle cell oncocytoma. In: Louis DN, Ohgaki $\mathrm{H}$, Wiestler OD, Cavenee WK, WHO Classification of Tumours of the Central Nervous System. Lyon, France: IARC Press 334-336.

59. Roncaroli F, Scheithauer BW, Cenacchi G, Horvath E, Kovacs K, et al. (2002) 'Spindle cell oncocytoma' of the adenohypophysis: a tumor of folliculostellate cells? Am J Surg Pathol 26: 1048-1055.

60. Mete O, Lopes MB, Asa SL (2013) Spindle cell oncocytomas and granular cell tumors of the pituitary are variants of pituicytoma. Am J Surg Pathol 37 1694-1699. 